Journal of Computer Science 4 (7): 585-590, 2008

ISSN 1549-3636

(C) 2008 Science Publications

\title{
Performance of Unequal Error Protection Using Maximum A- posteriori Probability Algorithm and Modified MAP in Additive White Gaussian Noise and Fading Channel
}

\author{
${ }^{1}$ Gnanasekaran T. and ${ }^{2}$ K.Duraiswamy \\ ${ }^{1}$ BannariAmman Institute of Technology, Sathyamangalam, TamilNadu, India \\ ${ }^{2} \mathrm{~K}$ S Rangasamy College of Technology, Tiruchengode, India
}

\begin{abstract}
Problem statement: In this study we propose a method to improve the performance of Maximum A-Posteriori Probability Algorithm, which is used in turbo decoder. Previously the performance of turbo decoder is improved by means of scaling the channel reliability value. Approach: A modification in MAP algorithm proposed in this study, which achieves further improvement in forward error correction by means of scaling the extrinsic information in both decoders without introducing any complexity. The encoder is modified with a new puncturing matrix, which yields Unequal Error Protection (UEP). This modified MAP algorithm is analyzed with the traditional turbo code system Equal Error Protection (EEP) and also with Unequal Error Protection (UEP) both in AWGN channel and fading channel. Result: MAP and modified MAP achieve coding gain of $0.6 \mathrm{~dB}$ over EEP in AWGN channel. The MAP and modified MAP achieve coding gain of 0.4 $\mathrm{dB}$ and $0.9 \mathrm{~dB}$ over EEP respectively in Rayleigh fading channel. Modified MAP in UEP class 1 and class 2 gained $0.8 \mathrm{~dB}$ and $0.6 \mathrm{~dB}$ respectively in AWGN channel where as in fading channel class 1 and 2 gained $0.4 \mathrm{~dB}$ and $0.6 \mathrm{~dB}$ respectively. Conclusion/Recommendations: The modified MAP algorithm improves the Bit Error Rate (BER) performance in EEP as well as UEP both in AWGN and fading channels. We propose modified MAP error correction algorithm with UEP for broad band communication.
\end{abstract}

Key words: Bit error rate, AWGN, SOVA, maximum a- posteriori probability, turbo code

\section{INTRODUCTION}

UEP Turbo Code ${ }^{[1,2]}$ is development of traditional Turbo code in practical application. In the application of some fields, information has different important degree, such as digital video broadcasting and digital audio broadcasting. The UEP Turbo Codes carry on extra protection to the important part in information source, thus improving the accuracy of decoding about the important information. Such unequal protection characteristic can be used for telephone communication of moving satellites and transmitting the picture data compressed, by setting information bit that should be protected carefully; the whole communication performance of some system would be improved. This study introduces an implementation of UEP Turbo Codes by designing a new puncturing matrix scheme. We assume the source encoders produce the binary symbol frames. Each frame of the source signal can be divided into important and not important information. As to the fixed code rate, decoding delay and complexity, better code scheme can get lower Bit Error Rate (BER) while decoding to the important information part, and can get relatively higher BER to the non important information part properly. For the decoding of traditional Turbo Codes, the BER have nothing to do with the position of information symbol, and these codes are called the Equal Error Protection (EEP) Turbo Codes.

\section{MATERIALS AND MATHODS}

Equal error protection turbo codes: Turbo Code is an outstanding channel code scheme, proposed by Frenchmen Berrou originally in $1993^{[3,4]}$. In Fig. 1 represent a generic Turbo Encoder with Equal Error Protection. The first block of data will be encoded by the RSC ENCODER1 (D1) block. The same block of information bits is interleaved by the Interleaver $(\mathrm{INT})^{[5,6]}$ and encoded by RSC ENCODER2 (D2). The code word in framed by concatenating $X_{K}$, $\mathrm{Y}_{1 \mathrm{~K}}, \mathrm{Y}_{2 \mathrm{~K}}$. The main purpose of the INT is to increase the minimum distance of the turbo code such that after correction in one dimension the remaining errors should become correctable error patterns in the second dimension. 


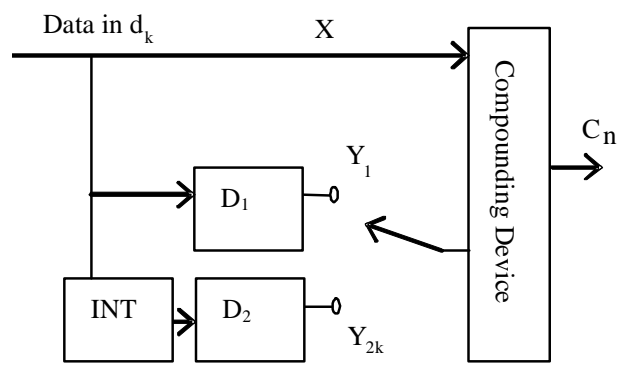

Fig. 1: Block diagram of Turbo Encoder

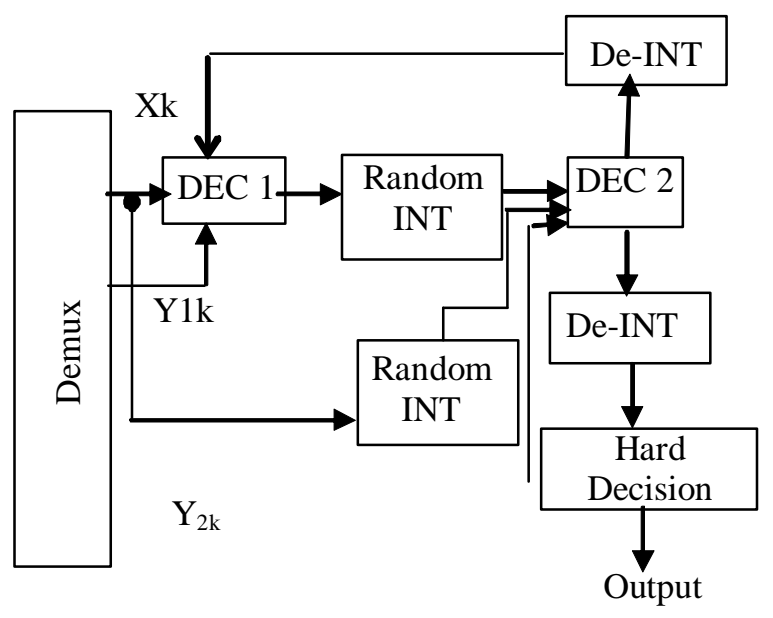

Fig. 2: The decoder of the Turbo Codes

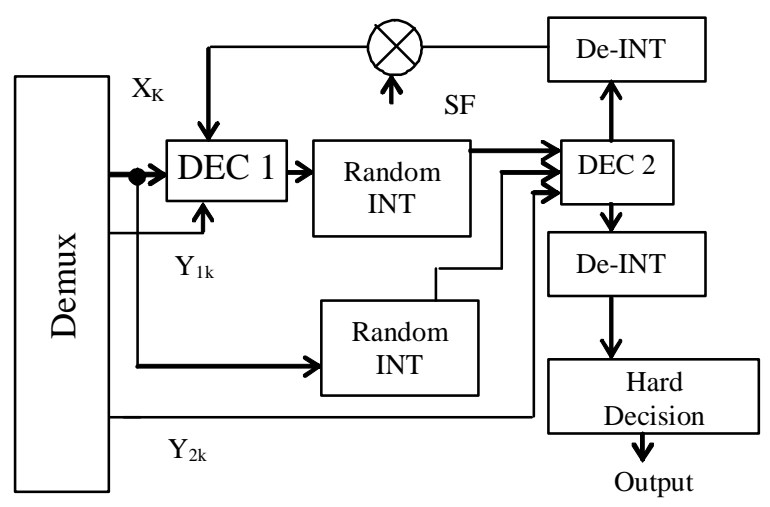

Fig. 3: The decoder of the Turbo Codes with single scaling factor

This is rate $1 / 3$ turbo code, the output of the turbo encoder being the triplet $\left(X_{K}, Y_{1 K}\right.$, and $\left.Y_{2 K}\right)$. This triplet is than modulated for transmission across the communication channels. Since the code is systematic, $\mathrm{d}_{\mathrm{K}}$ is the input data at time k. $Y_{1 k}$ and $Y_{2 K}$ are the two parity bits at time $\mathrm{k}$. The output of the encoder $\mathrm{C}$ is as shown below:

$\mathrm{C}=\left(\mathrm{X}_{\mathrm{K}}, \mathrm{Y}_{1 \mathrm{~K}}, \mathrm{X}_{\mathrm{K}}, \mathrm{Y}_{2 \mathrm{~K}}, \mathrm{X}_{\mathrm{K}}, \mathrm{Y}_{1 \mathrm{~K}}, \ldots\right)$

The decoding algorithms used are the MAP algorithm of Bahl ${ }^{[7]}$ modified MAP. Fig. 2 shows generic turbo decoder. In modified $\mathrm{MAP}^{[9]}$, the extrinsic information is multiplied by the scaling factor which is the empirical value; which enrich the extrinsic information to the decoder (DEC1) of Fig. 3. The soft outputs from the component decoders are typically represented in terms of the so-called Log-Likelihood Ratios (LLRs), the magnitude of which gives the sign of the bit, and the amplitude the probability of a correct decision. The LLRs are simply, as their name implies the logarithm of the ratio of two probabilities. For example, the LLR $\mathrm{L}\left(\mathrm{u}_{\mathrm{k}}\right)$ for the value of decoded bit $u_{k}$ is given by

$$
\mathrm{L}\left(\mathrm{u}_{\mathrm{k}}\right)=\ln \left(\frac{\mathrm{P}\left(\mathrm{u}_{\mathrm{k}}=+1\right)}{\mathrm{P}\left(\mathrm{u}_{\mathrm{k}}=-1\right)}\right)
$$

Where $\mathrm{P}\left(\mathrm{u}_{\mathrm{k}}=+1\right)$ is the probability that the bit $u_{k}=+1$, and similarly for $P\left(u_{k}=-1\right)$. Notice that the two possible values of the bit $u_{k}$ are taken to be +1 and -1 , rather than 1 and 0 . The decoder operates iteratively. The error decrease as the number of iterations increases. When the iteration is finished, the soft outputs of second decoder are deinterleaved and a hard decision is made to obtain message bits $\mathrm{C}$.

Unequal error protection turbo code: The UEP Turbo Codes carry on extra protection to the important part in information source. The UEP is implemented by designing a new puncturing matrix scheme to existing turbo code. Unequal Error Protection is made up of two same RSC component encoders and one pseudorandom interleaver. For being convenient, we can regard a trellis termination Turbo Codes as a section of systematic block codes ${ }^{[8]}$. As Fig. 4 shown, the input arrays turn into parity bits of $\mathrm{Y}_{1 \mathrm{k}}$ and $\mathrm{Y}_{2 \mathrm{~K}}$ through two RSC component encoders and interleavers. We can raise the rate by puncturing redundant vectors. Vector y $\left(\mathrm{Y}_{1 \mathrm{k}}\right.$ and $\left.\mathrm{Y}_{2 \mathrm{~K}}\right)$ can be expressed with binary vector Pi. Binary bits 0 and 1 in the vector show puncturing and un-puncturing in this location of information respectively. 
Let $w(p)$ denote Hamming weight then the rate of the resulting punctured Turbo Codes with trellis termination is,

Where $t$ is the number of input symbols necessary for trellis termination. In EEP, puncturing matrix has a unified form, for example:

The parity bits $\mathrm{y}_{1 \mathrm{k}}, \mathrm{y}_{2 \mathrm{k}}$ are through puncturing matrix $\mathrm{y}_{1 \mathrm{k}}, \mathrm{y}_{2 \mathrm{k}}$ and information bits $\mathrm{x}_{\mathrm{k}}$ are formatted as the following form:

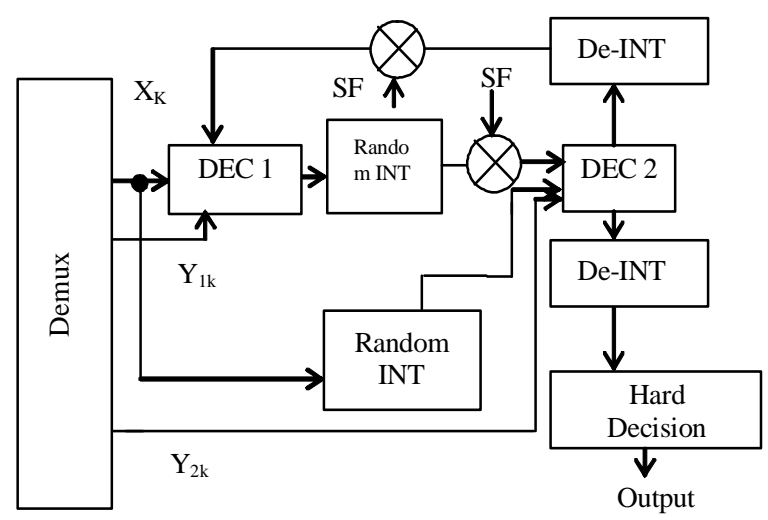

Fig. 4: The decoder of the Turbo Codes with double scaling factor

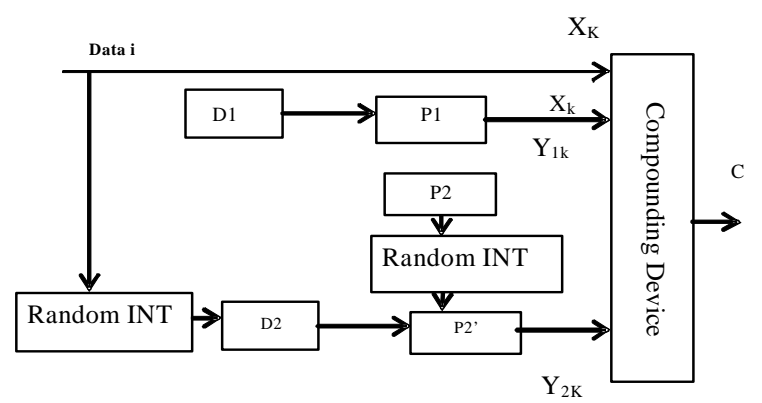

Fig. 5: Block diagram of unequal error protection Turbo encoder

$$
\begin{aligned}
& R=\frac{k-t}{k+w\left(p_{1}\right)+w\left(p_{2}\right)} \\
& P=\left\{\begin{array}{ll}
1 & 0 \\
0 & 1
\end{array}\right\} \\
& C_{n}=\left\{X_{1}, Y_{1 K 1}, X_{2}, Y_{2 K 1}, X_{3}, Y_{1 K 3}, \cdots\right\}
\end{aligned}
$$

$$
\mathrm{C}=\left\{\begin{array}{ccc}
\mathrm{C}_{1}^{1} & \ldots \ldots . & \mathrm{C}_{28}^{1} \\
\mathrm{C}_{29}^{2} & \ldots \ldots . . & \mathrm{C}_{56}^{2} \\
\mathrm{C}_{57}^{3} & \ldots \ldots . . & \mathrm{C}_{182}^{3}
\end{array}\right\}
$$

Unequal Error Protection is generated by assuming the information $\mathrm{m}=\mathrm{d}_{\mathrm{k}}$ of size $\mathrm{k}$ are partitioned into $\left\{\mathrm{C}_{\mathrm{i}}, \mathrm{i} \in\left[1, \mathrm{C}_{\max }\right]\right\}$ classes, according to importance criterion. $\left\{\mathrm{k}_{\mathrm{i}}, \mathrm{i} \in\left[1, \mathrm{C}_{\max }\right]\right\}$ Shows the set of the length of each $\mathrm{Ci}$ class. Fig. 5 shows block diagram of unequal error protection turbo encoder. The rate in the unpunctured Turbo Codes system (EEP) is $1 / 3$. Suppose $\mathrm{C}_{\max }=3$, the unequal error protection turbo codes increase the redundant information in $\mathrm{C} 1$ and $\mathrm{C} 2$ classes. In order to balance the rate of total turbo codes, it is necessary to reduce the redundant information of C3 corresponsive. Two puncturing matrix are designed separately $\left(\mathrm{P}_{1}, \mathrm{P}_{2}\right)$. Parity bits $\mathrm{y}_{1 \mathrm{k}}$ and $\mathrm{y}_{2 \mathrm{k}}$ pass one's own unequal puncturing matrix $\mathrm{P}^{1}$ and $\mathrm{P}^{2}$, and then are sent to the compounding device respectively. The binary bit 1 in the puncturing matrix means keeping the corresponding bit, while the binary bit 0 means deleting the corresponding bit. Because the information passes the interleaver, and is encoded by the RSC component encoder2, it is necessary to interleave $\mathrm{P}^{2}$, before puncturing $\mathrm{Y}_{2 \mathrm{~K}}$. So, the operation principles of the unequal error protection turbo codes encoder are as follows: According the structure of frame to design the puncturing matrix. Firstly: we must accord the importance of each part of information and equation (3) to confirm the partial rate of $\mathrm{C}_{\mathrm{i}}$ class and Hamming weight of puncturing matrix $\mathrm{P}^{1}, \mathrm{P}^{2}$. Then, we need to design the structure of puncturing matrix $\mathrm{P}^{1}$ and $\mathrm{P}^{2}$, to confirm the protection situation of the information bits to be encoded. The information to be encoded passes two component encoders and two puncturing matrix, and then get the parity bits $\mathrm{Y}_{1 \mathrm{k}}, \mathrm{Y}_{2 \mathrm{~K}} . \mathrm{X}_{\mathrm{k}}, \mathrm{Y}_{1 \mathrm{k}}$ and $\mathrm{Y}_{2 \mathrm{~K}}$ are input to the channel through compounding device.

In our experiment the generator matrix of Turbo Codes is $(7,5)$, the size of the frame to be encoded is 182. We apply EEP and UEP to the information. The frame is divided into 3 classes according to the importance. And let $\mathrm{k} 1=28, \mathrm{~K} 2=28$ and $\mathrm{k} 3=126$. The Table 1 provides the contrast of EEP and UEP. Turbo codes and redundancy weight of each class.

The partial rate of $\mathrm{C} 1$ and $\mathrm{C} 2$ in UEP are both $1 / 3$. The partial rate of $\mathrm{C} 3$ is 0.64285 . Without loss of generality, suppose the distribution of important bits in the information has the following forms: 
Table 1: The contrast between EEP and UEP

\begin{tabular}{lllll}
\hline Classes & 1 & 2 & 3 & \\
\hline Symbols & 28 & 28 & 126 & \\
Code rate & EEP & $1 / 2$ & $1 / 2$ & $1 / 2$ \\
& UEP & $1 / 3$ & $1 / 3$ & 0.64285 \\
Redundancy weight & EEP & 28 & 28 & 126 \\
& UEP & 56 & 56 & 70 \\
\hline
\end{tabular}

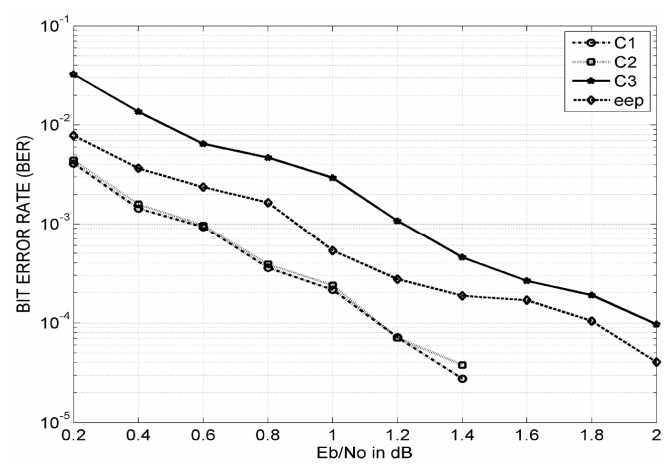

Fig. 6: Unequal Error Protection using MAP in AWGN channel

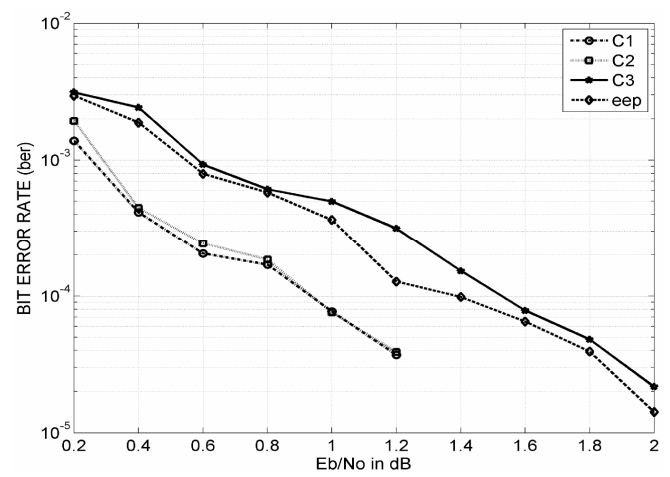

Fig. 7: Unequal Error Protection using Modified MAP in AWGN channel

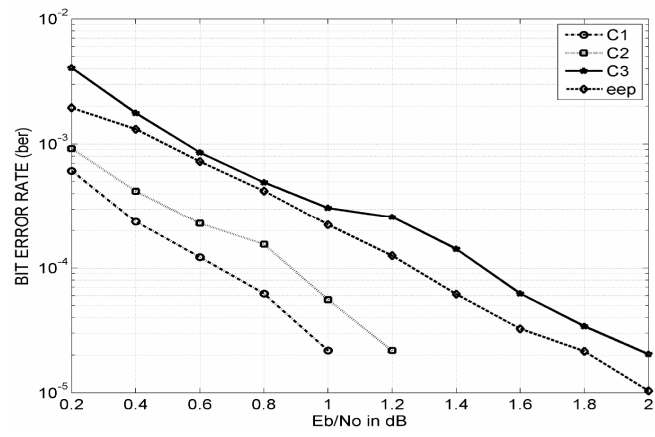

Fig. 8: Unequal Error Protection using Modified MAP with double scaling factor in AWGN channel
As we can see class 1 and class 2 have kept all parity information of two component encoders. The information bits in class 3 have been punctured according to the Hamming weight of redundancy vector. Table 2 and Table 3 show the puncturing matrix of $\mathrm{P} 1$ and $\mathrm{P} 2$ respectively as mention in the Fig.2.

Fig. 6 and 7 shows the simulated result for the MAP algorithm modified MAP in AWGN channel. The UEP Turbo Codes achieves a coding gain over the EEP codes of about $0.6 \mathrm{~dB}$ for class 1 (C1) and class 2 (C2) messages for both MAP and modified MAP. But in modified MAP BER is reduced over all.

Table 4: shows the allocation of redundancy bit for different classes of message to simulate the MAP algorithm with double scaling factor. Fig. 8 shows the simulated result for modified MAP with double scaling factor. Here in class 1 gained $0.8 \mathrm{~dB}$ and class 2 gained $0.6 \mathrm{~dB}$ over EEP in AWGN channel.

Table 2: Puncturing Matrix P1

\begin{tabular}{llllll}
\hline $\mathrm{P}_{1}^{1}$ & $\mathrm{P}_{2}^{1}$ & $\mathrm{P}_{3}^{1}$ & $\mathrm{P}_{4}^{1}$ & $\ldots \ldots \ldots \ldots \ldots$ & $\mathrm{P}_{14}^{1}$ \\
$\mathrm{P}_{15}^{1}$ & $\mathrm{P}_{16}^{1}$ & $\mathrm{P}_{17}^{1}$ & $\mathrm{P}_{18}^{1}$ & $\ldots \ldots \ldots \ldots . \mathrm{P}_{56}^{1}$ & \\
$\mathrm{P}_{57}^{0}$ & $\mathrm{P}_{58}^{1}$ & $\mathrm{P}_{59}^{0}$ & $\mathrm{P}_{60}^{1}$ & $\ldots \ldots \ldots \ldots \ldots \mathrm{P}_{70}^{0}$ & \\
\hline
\end{tabular}

\begin{tabular}{llllll}
$\mathrm{P}_{169}^{0}$ & $\mathrm{P}_{170}^{0}$ & $\mathrm{P}_{171}^{1}$ & $\mathrm{P}_{172}^{0}$ & $\ldots \ldots \ldots \ldots \ldots \ldots$ & $\mathrm{P}_{182}^{0}$ \\
\hline
\end{tabular}

Table 3: Puncturing Matrix P2

\begin{tabular}{llllll}
\hline $\mathrm{P}_{1}^{1}$ & $\mathrm{P}_{2}^{1}$ & $\mathrm{P}_{3}^{1}$ & $\mathrm{P}_{4}^{1}$ & $\ldots \ldots \ldots \ldots \ldots$ & $\mathrm{P}_{14}^{1}$ \\
$\mathrm{P}_{15}^{1}$ & $\mathrm{P}_{16}^{1}$ & $\mathrm{P}_{17}^{1}$ & $\mathrm{P}_{18}^{1}$ & $\ldots \ldots \ldots \ldots . \mathrm{P}_{56}^{1}$ & \\
$\mathrm{P}_{57}^{0}$ & $\mathrm{P}_{58}^{1}$ & $\mathrm{P}_{59}^{0}$ & $\mathrm{P}_{60}^{1}$ & $\ldots \ldots \ldots \ldots \ldots \mathrm{P}_{70}^{0}$ & \\
\hline
\end{tabular}

\begin{tabular}{llllll}
$\mathrm{P}_{169}^{1}$ & $\mathrm{P}_{170}^{1}$ & $\mathrm{P}_{171}^{0}$ & $\mathrm{P}_{172}^{1}$ & $\ldots \ldots \ldots \ldots \ldots \ldots$ & $\mathrm{P}_{182}^{1}$ \\
\hline
\end{tabular}

Table 4: The contrast between EEP and UEP with Double Scaling Factor

\begin{tabular}{lllll}
\hline Classes & 1 & 2 & 3 & \\
\hline Symbols & 28 & 28 & 126 & \\
Code rate & EEP & $1 / 2$ & $1 / 2$ & $1 / 2$ \\
& UEP & $1 / 3$ & 0.3888 & 0.6057 \\
Redundancy weight & EEP & 28 & 28 & 126 \\
& UEP & 56 & 44 & 82 \\
\hline
\end{tabular}

Fig. 9 and 10 shows the simulated result for the MAP and modified MAP algorithm in Rayleigh fading channel. Fig. 11 shows the simulated result for modified MAP with double scaling factor. Here in class 1 gained $0.4 \mathrm{~dB}$ and class 2 gained $0.6 \mathrm{~dB}$ at $1.2 \mathrm{~dB}$ over EEP in fading channel. 


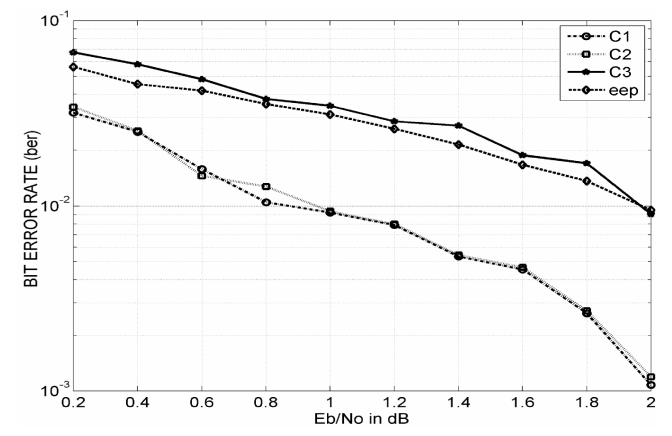

Fig. 9: Unequal Error Protection using MAP Rayleigh fading channel

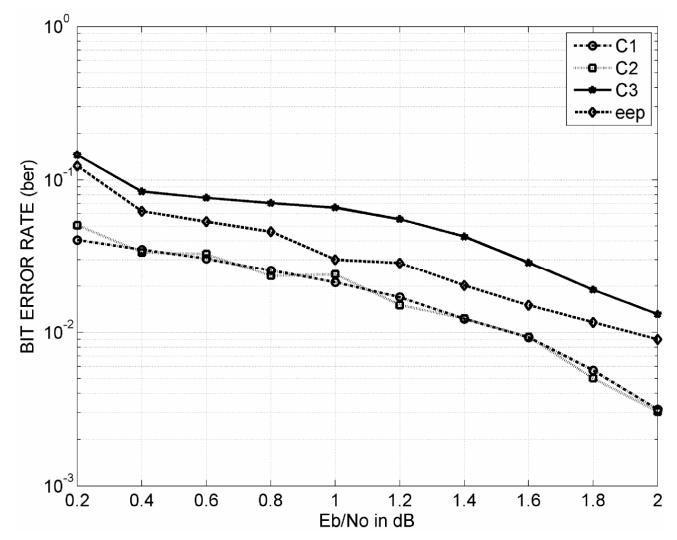

Fig. 10: Unequal Error Protection using Modified MAP in Rayleigh fading channel

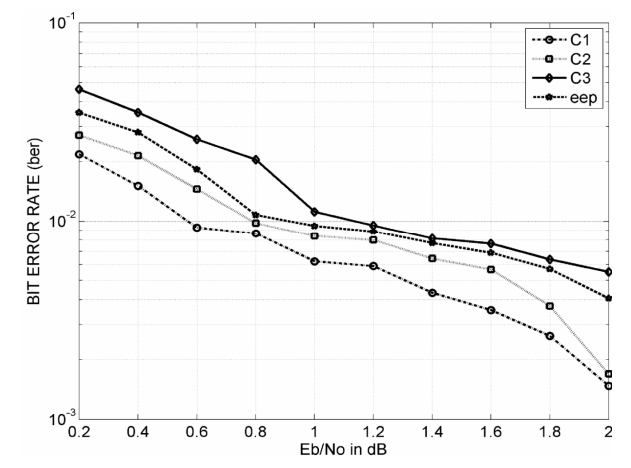

Fig. 11: Unequal Error Protection using Modified MAP with double scaling factor in Rayleigh fading channel

We have simulated the entire Turbo code ic Turbo encoder and Turbo decoders using MatLab 7.4 R2007a codes and Simulink as Graphical User Interface (GUI).

\section{RESULTS}

The simulation parameters are given below Channel: AWGN and Raleigh Fading channel. Modulation: Binary Phase shift Keying (BPSK) Component encoder: Recursive convolution codes (RSC)

$\mathrm{n}=2, \mathrm{k}=1, \mathrm{~K}=3, \mathrm{G} 0=7, \mathrm{G} 1=5$

Interleaver: 2048 bit random interleaver Iteration: 8

Rate: $1 / 2$

The results are shown in Fig 6 to 11 .

\section{DISCUSSION}

In this paper we proposed a new Unequal Error Protection Turbo Codes using modified MAP. The experimental results have proved that it not increasing the system complexity. MAP and modified MAP achieve coding gain of $0.6 \mathrm{~dB}$ over EEP in AWGN channel. The MAP and modified MAP achieve coding gain of $0.4 \mathrm{~dB}$ and $0.9 \mathrm{~dB}$ over EEP respectively in Rayleigh fading channel. Modified MAP with double scaling factor class 1 and class 2 gained $0.8 \mathrm{~dB}$ and 0.6 $\mathrm{dB}$ respectively in AWGN channel where as in fading channel UEP class 1 and 2 gained $0.4 \mathrm{~dB}$ and $0.6 \mathrm{~dB}$ respectively.

\section{CONCLUSION}

The modified MAP produces better performance than MAP both in EEP and UEP. It also produces better performance both AWGN and Fading channel. Comparing EEP and UEP, UEP produces better performance. So we propose modified MAP turbo code with UEP for broad band communication.

\section{REFERENCES}

1. Zude Zhou and Chao Xu, 2005. An improved Unequal error protection turbo codes. Proceedings of International Conference on Wireless Communications, Networking and Mobile Computing, Sep. 23-26, IEEE Xplore, pp: 284-287. Doi: 10.1109/WCNM.2005.1544037

2. Neri, M., A. Vanelli-Coralli and G.E. Corazza, 2003. Unequal error protection: A turbo multi level coding approach. Proceeding of the Global Telecommunications Conference, Dec. 1-5, IEEE Xplore, pp: 102-106. Doi: 10.1109/GLOCOM.2003.1258211 
3. Berrou, C., A. Glavieux and P. Thitimajshima, 1993. Near Shannon limit error-correcting coding and decoding: Turbo-codes. Proceeding of IEEE International Conference on Communications, Geneva Technical Program, May 23-26, IEEE Xplore, Geneva, Switzerland, pp: 1064-1070. Doi: 10.1109/ICC.1993.397441

4. Zhang and Zong Cheng, 2003. The Application and Principle of Error Correction Codes. Beijing, China: Publishing House of Electronics Industry, pp: 246-249.

5. Blackert, W.J., E.K. Hall and S.G. Wilson, 1995. Turbo code termination and interleaver conditions. Electronics Lett., 31: 2082-2084. http://ieeexplore. ieee.org/xpl/freeabs_all.jsp?arnumber $=480720$.

6. Caire, G. and G. Lechner, 1996. Turbo codes with unequal error protection. Electron. Lett., 32: 629-631. http://ieeexplore.ieee.org/xpls/abs_ all.jsp?arnumber $=491863$
7. Hagenauer, J. and P. Hoeher, 1989. Viterbi algorithm with soft-decision outputs and its applications. Global Telecommunications Conference, 1989 and Exhibition, Communications Technology for the 1990s and Beyond GLOBECOM '89., IEEE, Dallas, USA., pp: 1680-1686. Doi: 10.1109/GLOCOM.1989.64230

8. Bahl, L.R., J. Cocke, F. Jelinek and J. Raviv, 1974. Optimal decoding of linear codes for minimizing symbol error rate. IEEE Trans. Inform. Theory, 2: 284-287. http://ieeexplore.ieee.org/xpl/freeabs _all.jsp?arnumber $=1055186$

9. Coastas Chaikalis James, M. Noras and Felip Riera-Palou, 2005. Improving the reconfigurable SOVA /log MAP Turbo coder for 3GPP university of Bradford. Department of Electronics and Telecommunication,Bradford, West Yorkshire, BD7,1DP,UK. 84:1957-1972 